\title{
Increasing the Cruise Range and Reducing the Capital Cost of Electric Vehicles by Integrating Auxiliary Unit with the Traction Drive
}

\author{
N. Satheesh Kumar \\ Energy Research Institute@ NTU (ERI@N), Interdisciplinary Graduate School, Nanyang Technological University, Singapore 639798
}

Correspondence should be addressed to N. Satheesh Kumar; sendsatheesh@gmail.com

Received 27 July 2015; Accepted 14 December 2015

Academic Editor: Alain Lambert

Copyright (C) 2016 N. Satheesh Kumar. This is an open access article distributed under the Creative Commons Attribution License, which permits unrestricted use, distribution, and reproduction in any medium, provided the original work is properly cited.

\begin{abstract}
Poor cruise performance of Electric Vehicles (EVs) continues to be the primary reason that impends their market penetration. Adding more battery to extend the cruise range is not a viable solution as it increases the structural weight and capital cost of the EV. Simulations identified that a vehicle spends on average $15 \%$ of its total time in braking, signifying an immense potential of the utilization of regenerative braking mechanism. Based on the analysis, a $3 \mathrm{~kW}$ auxiliary electrical unit coupled with the traction drive during braking events increases the recoverable energy by $8.4 \%$. In addition, the simulation revealed that, on average, the energy drawn from the battery is reduced by $3.2 \%$ when traction drive is integrated with the air-conditioning compressor (an auxiliary electrical load). A practical design solution of the integrated unit is also included in the paper. Based on the findings, it is evident that the integration of an auxiliary unit with the traction drive results in enhancing the energy capturing capacity of the regenerative braking mechanism and decreases the power consumed from the battery. Further, the integrated unit boosts other advantages such as reduced material cost, improved reliability, and a compact and lightweight design.
\end{abstract}

\section{Introduction}

At present, the batteries, which power the Electric Vehicles (EVs), have a poor energy density in comparison to gasoline. Gasoline has specific energy of $12 \mathrm{kWh} / \mathrm{kg}$; in contrast, an energy storage system based on advanced nickel-metal hydride has a specific energy density of $100 \mathrm{Wh} / \mathrm{kg}$ [1]. Consequently, EVs tend to be equipped with bulky batteries to maximise their energy storing capacity. The combination of poor energy density and high power electrical loads from the traction motor and auxiliary electrical loads expedites the battery drain, leading to its poor cruise range performance.

In a gasoline-powered vehicle, Internal Combustion (IC) engine drives the brake pump, power-steering pump, radiator fan, and so forth through a belt-and-pulley drive. Meanwhile, accessories requiring intermediate power, such as an A/C compressor, are connected with the engine through a clutch mechanism to regulate their speed. This method of delivering power to accessory is well suited as the engine operates continuously even when the vehicle is at a complete standstill. However, a similar method cannot be utilized for EVs as the traction motor does not operate continuously. Therefore, EVs typically employ multiple motor drives to power continuous and intermediate accessories. The dedicated motor drives provide the flexibility to operate the accessories at an independent torque and speed based on the operating requirements and can be switched off when needed.

Each of the motor drives powering the accessories in an EV has its own motor housing, cooling mechanism (if needed), electronic control unit, and a DC-to-DC converter to step down the battery voltage as required. Though these drives provide easy control over the driven system, the added component count contributes to the overall cost of an EV and decreases the net reliability. In addition, these drives could only obtain the electrical power from the battery. Therefore, when an EV operates in recuperation mode, the forward 
momentum of the vehicle has to undergo a number of energy conversation processes before the energy is made available to the accessory motor drives.

This paper analyses a novel design solution geared towards improving the overall efficiency, reliability, and cost saving by integrating the $\mathrm{A} / \mathrm{C}$ compressor drive with the traction motor. The integrated unit is expected to operate close to $100 \%$ efficiency during recuperation mode. The unprecedented improvement in efficiency is achieved through the direct mechanical coupling of the traction motor with the A/C compressor during braking events. The mechanical configuration of the unit is such that the torque and speed characteristics of traction and compressor motors can be independently controlled during drive mode. In addition to improved efficiency, the integrated unit boosts numerous other advantages such as compact design and weight saving.

Motivation for Study. EVs have been commercially available since the later period of the 20th century. However, vehicles powered by IC engines continue to dominate the current private transport market share. To date, the low range for a given battery charge and high capital cost associated with the EV continue to remain the key factors hindering its widespread acceptance. Hence, the challenges faced by EVs are to come to par with that of gas-powered vehicles in terms of performance levels, comfort, and cost. These factors provide the stimulus to identify and investigate means to improve the competitiveness of an EV. This paper explores the possibility of integrating the A/C compressor with the EV's traction motor to enhance the efficiency and cost saving of an EV.

Research Novelty. When a conventional car brakes, the forward momentum of the car is primarily dissipated as heat energy in the brake pads. Undoubtedly, this not only results in energy wastage, but also wears out the brake pads. To counter this, hybrid vehicles and EVs are fitted with regenerative braking mechanism. The principal purpose of this mechanism is to capture the kinetic energy of the car during braking events and store it in some form of energy storage device. Typically, the regenerative braking mechanism consists of an electric motor that acts as a generator and a battery to store the power produced by the generator for subsequent usage. Since the regenerative braking mechanism converts majority of the kinetic energy of the car to electrochemical energy (for storage in battery), the energy wasted as heat in the brake pads is reduced and the overall efficiency and range of the EV improve.

However, the key shortfall associated with this method is that the kinetic energy of the vehicle has to be first converted to electrical energy prior to being routed to the battery. As with any energy conversion process, the flow of energy from one domain to the other will incur losses due to inefficiencies. In addition, when the recuperated stored energy is drawn from the battery, it once again has to be converted from electrochemical energy to a suitable form required by the point of utilization. Therefore, the key in improving the efficiency of the regenerative braking mechanism is to eliminate the energy conversions by direct and immediate utilization of

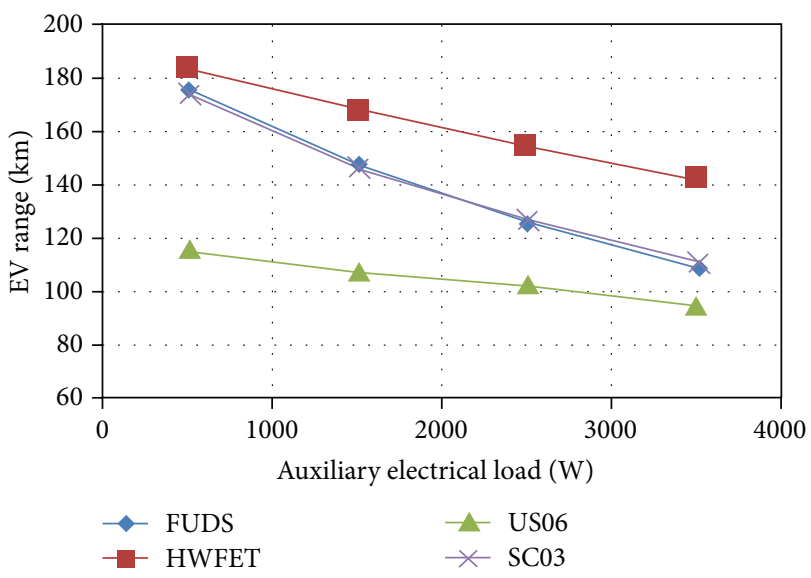

FIgURE 1: Impact of auxiliary electrical load on EV's range for various drive cycles [1].

the captured energy. The paper first investigates the advantage of integrating an auxiliary unit with the traction drive and then simulates a test vehicle in Simulink ${ }^{\circledR}$ to predict the reduction in battery energy consumption attained by the integrated unit. Further, the paper provides a practical design solution demonstrating the feasibility of integrating an A/C compressor with the traction drive.

\section{Literature Review}

2.1. Effect of A/C Load on EV's Range. On average, an automobile is driven for 250 hours per year [2]. This roughly equates to 115 hours of $\mathrm{A} / \mathrm{C}$ operation [3], corresponding to $45 \%$ of the vehicle usage. The $\mathrm{A} / \mathrm{C}$ system in an EV acts as a parasitic load, as the system draws in energy only when the passenger chooses to turn it on. Such an electrical load is often termed as "off-cycle" electrical load. Other off-cycle loads include wipers, stereo system, heated seats, headlights, and defrosters. Although these loads tap into the battery power, the $\mathrm{A} / \mathrm{C}$ system is unique as it puts on a considerably larger electrical load. This strains the battery and results in rapid depletion of the stored energy. In fact, it is estimated that the use of air conditioning typically results in a $33 \%$ decrease in the EV's range [4].

Farrington and Rugh [5] provided a comprehensive insight into the detrimental impact of an auxiliary electrical load on the EV's range performance. The study simulated a five-passenger EV powered by NiMH battery on ADVISOR (Advanced Vehicle Simulator). The flexibility of the simulation platform allowed scheduled application of the auxiliary electrical loads based on US EPA certification procedures: FUDS, HWFET, SC03, and US06. To appreciate the significance of the findings, consider an EV operating in SC03 drive cycle with a base electrical load of 500 W. Switching on a $1500 \mathrm{~W}$ electrical load increases the net auxiliary load to $2000 \mathrm{~W}$, which drastically decreases the EV's cruise range by $22 \%$ (Figure 1 ). The paper identified A/C compressor as the single largest electrical load that leads to a drastic reduction in vehicle's range. In addition, the authors concluded that even a marginal improvement in $\mathrm{A} / \mathrm{C}$ compressor efficiency would 


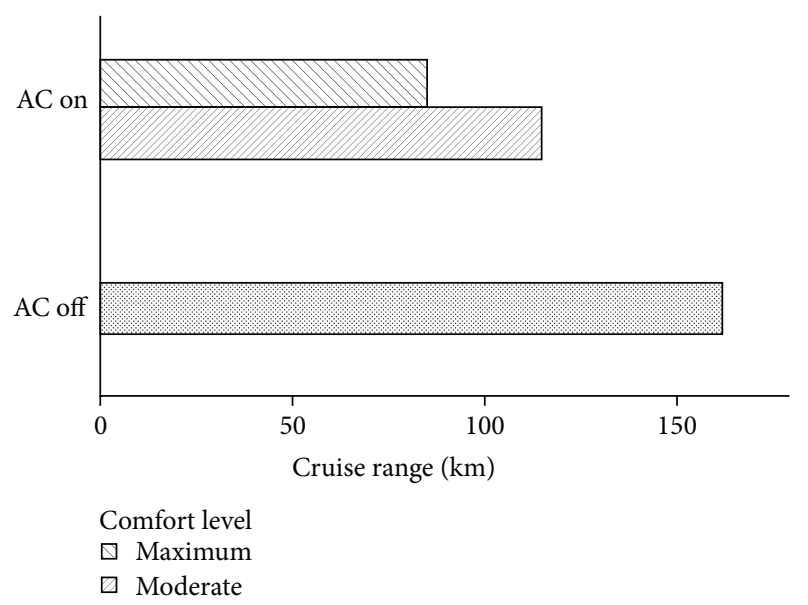

Figure 2: Impact of A/C on i-MiEV's cruise range [6].

result in a huge impact on energy saving due to the volume of new EVs sold each year.

In another study [6], Mitsubishi Motors subjected their recent $\mathrm{EV}, \mathrm{i}-\mathrm{MiEV}$, to a number of tests to measure the drop in cruise range due to the operation of $\mathrm{A} / \mathrm{C}$. The maximum cruise range of the vehicle was established by conducting the first run with $\mathrm{A} / \mathrm{C}$ turned off. In the subsequent runs, the $\mathrm{A} / \mathrm{C}$ unit was operated with moderate and maximum settings to determine its effect on the cruise range. Based on the plot (Figure 2), it can be deduced that cruise range decreases by $30 \%$ when $\mathrm{A} / \mathrm{C}$ is operated with moderate settings and by a staggering $48 \%$ when operated with maximum settings.

\subsection{Advantages of Integrating Traction and Compressor} Motors. Su and Hsu [7] explored the concept of electronic integration of the traction and compressor motors. The motive for such an integration is to reduce component count and minimize cost and the overall size of the compressor motor. With reference to Figure 3, Su and Hsu explain that, in a conventional system, independent inverters control the traction and the compressor motors. In this case, two three-phase motors and inverters are required for troublefree operation and independent speed regulation of the motors. Su and $\mathrm{Hsu}$ proposed replacing the three-phase compressor motor with a low-cost two-phase motor and inverter. Comparing Figures 3(a) and 3(b), it can be noted that the electrical integration of the two-phase inverter with that of the three-phase inverter results in fewer parts and allows the possibility of sharing the DC bus filter capacitor and gate drive power supply system. In general, the integrated circuit decreases the manufacturing cost and time and slashes the component count by one-third [7].

Apart from electrical integration, the traction and compressor motors can be physically integrated for a number of other reasons. The advantages include the following:

(i) Elimination of independent cooling systems for each motor.

(ii) Minimisation of external electrical cable. (iii) Weight and space saving as the motor housing can be shared.

(iv) Reduced parts count and increased reliability.

These advantages are attractive for the automotive industry as they enable the EVs to operate at higher efficiency, improved reliability, and decreased maintenance and manufacturing cost.

\section{Analysis and Discussion}

3.1. Regenerative Braking. When a vehicle brakes, the kinetic energy of the vehicle has to be absorbed to bring the vehicle to a stop. In a conventional vehicle, the brake pads, frictional resistance (traction), and aerodynamic losses help in dissipating the kinetic energy. However, in a vehicle fitted with a regenerative braking mechanism, the bulk of the kinetic energy is captured and directed through a number of devices before being stored in the battery. Figure 4 depicts the energy flow diagram during a regenerative braking event. Essentially, the diagram identifies the direction in which the energy flows and the major losses that occur along the energy flow path.

With reference to the energy flow diagram (Figure 4), note that it is still possible to incur braking losses in a vehicle equipped with regenerative braking mechanism if the drive motor is not capable of generating the required braking torque. Typically, the maximum generated power $\left(P_{\text {gen,max }}\right)$ during the recuperation mode is limited to the driving power of the motor to ensure that the motor operates within its designed electrical limits. Therefore, it is favourable to use electric motors with large power ratings to maximize the recoverable energy. However, the usage of unnecessarily large drive motor increases the structural weight and may result in locking the vehicle's wheels as discussed in subsequent analysis.

3.2. Regenerative Braking Simulation. This section models the velocity of the EV and the forces at work during a braking event. The specifications of the vehicle to be simulated are tabulated in Table 1 .

Figure 5 depicts the Free Body Diagram (FBD) of the EV in a recuperation mode subjected to constant deceleration, $-a$.

The vehicle speed can be described by

$$
V(t)=V_{0}-a \cdot t,
$$

where $V_{0}$ represents the initial velocity of the vehicle.

Adopting a noninertial frame of reference, the forward inertial force $\left(F_{\text {int }}\right)$ is given by

$$
F_{\text {int }}=m \cdot a,
$$

where $a$ represents the acceleration rate measured with respect to an inertial reference frame.

The four forces countering the forward inertia of the car are the traction, aerodynamic drag, frictional braking, and the regenerative braking force created by the motor functioning as a generator. The aerodynamic drag and the regenerative 
TABLE 1: Simulated vehicle parameters.

\begin{tabular}{lcc}
\hline Category & Parameter & Value \\
\hline & Vehicle type & $1450 \mathrm{~kg}$ \\
& Vehicle mass & $0.20 \mathrm{~m}$ \\
Vehicle & Tyre radius & 0.0015 \\
& Coefficient of friction between tyre and road & 0.30 \\
& Coefficient of drag $\left(C_{d}\right)$ & $0.60 \mathrm{~m}^{2}$ \\
\hline & Projected frontal area & $35 \mathrm{~kW}$ \\
Traction motor and transmission & Traction motor rated power & $2000 \mathrm{RPM}$ \\
& Motor based speed $\left(N_{\text {base }}\right)$ & 6 \\
Electrical accessory load & Transmission ratio $(r)$ & One-speed fixed gear \\
& Transmission type & 0.90 \\
\hline
\end{tabular}

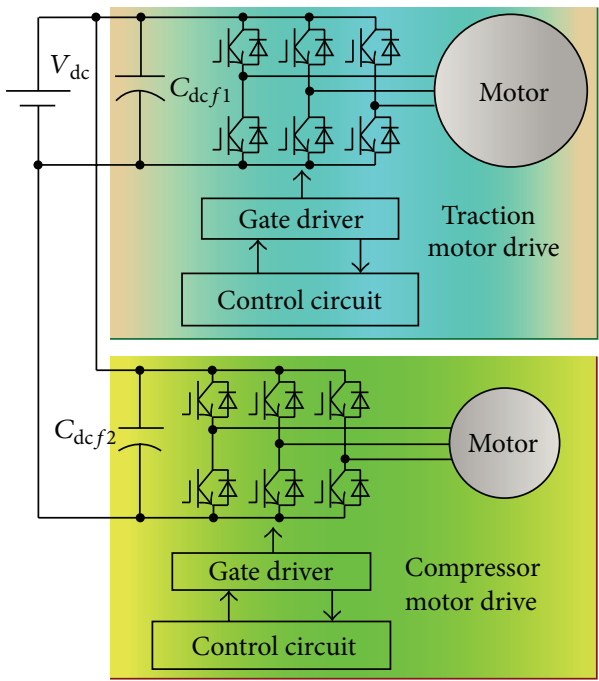

(a)

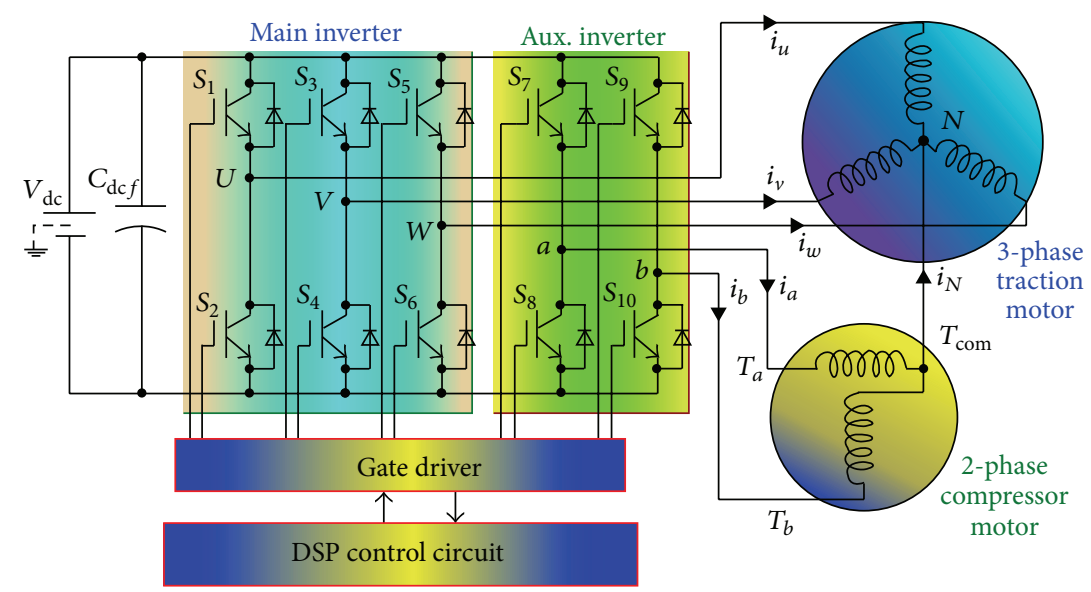

(b)

Figure 3: (a) A conventional configuration of traction and compressor motors controlled by independent inverters [7]. (b) Electrically integrated traction and compressor motors [7].

braking force are functions of vehicle's instantaneous velocity while the traction force remains constant.

Assuming the vehicle's weight is evenly distributed among the four wheels, the net rolling resistance due to the friction between the tyre and road is given by

$$
F_{\mathrm{tr}}=\mu \cdot m g
$$

The drag force is described by

$$
F_{\mathrm{dg}}(t)=\frac{1}{2} \rho[V(t)]^{2} A C_{d}
$$

The regenerative braking force produced by the motor depends on the motor's torque-speed characteristics.
The torque-speed characteristics of an ideal motor can be described by the following piecewise function:

$$
T_{\text {reg }}= \begin{cases}\frac{P_{\max } \cdot 60}{2 \pi \cdot N_{\text {base }}} & \text { if } N_{\text {motor }} \leq N_{\text {base }} \\ \frac{P_{\max } \cdot 60}{2 \pi \cdot N_{\text {motor }}} & \text { if } N_{\text {motor }} \geq N_{\text {base }}\end{cases}
$$

Given the base speed $\left(N_{\text {base }}\right)$ and maximum power $\left(P_{\max }\right)$, (5) can be used to generate torque-speed characteristics plot for various motor configurations. For the purpose of comparison, assuming a fixed base speed of 2000 RPM and varying the maximum power yield the plot shown in Figure 6. Analysis of the plot conveys that a motor with larger maximum power can produce a higher torque at lower speeds. 


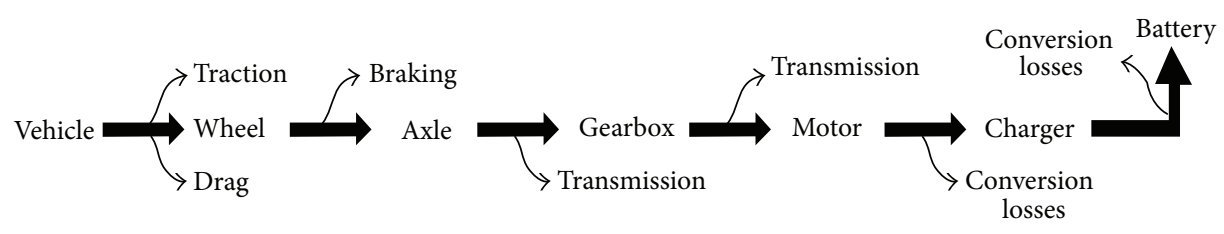

FIGURE 4: Energy flow diagram during regenerative braking.

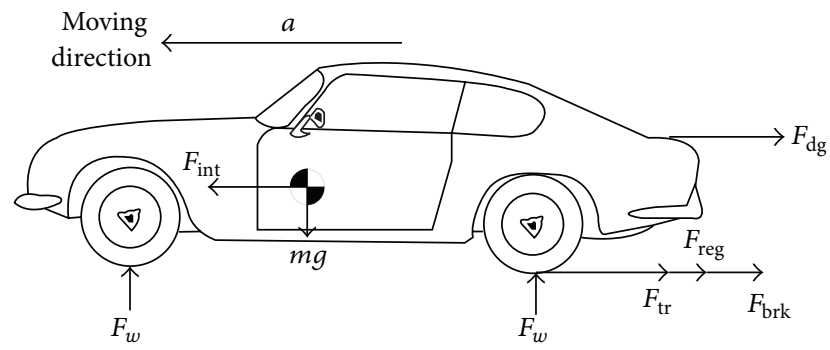

FIGURE 5: FBD of a vehicle in a regenerative braking mode under constant acceleration.

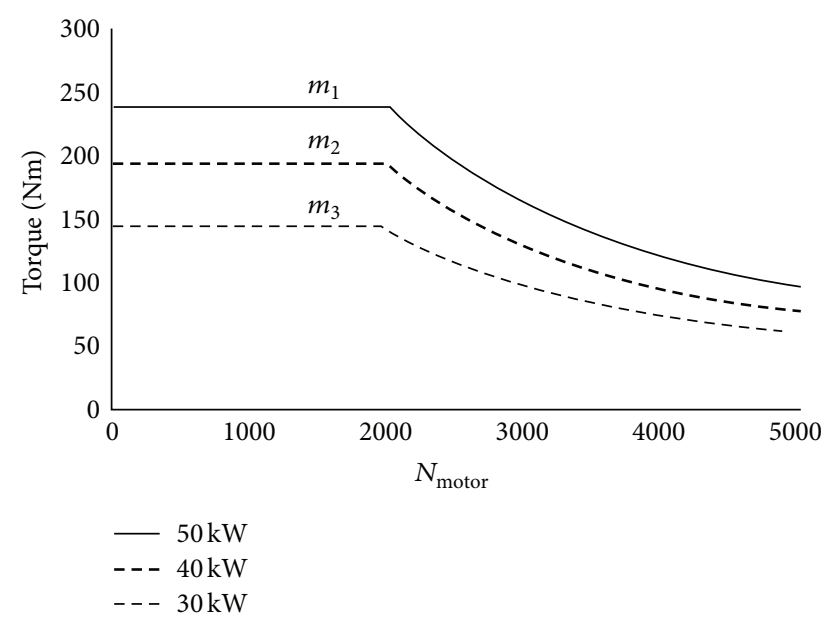

FIgURE 6: Motor torque-speed curves, where $m_{1}, m_{2}$, and $m_{3}$ are the weight of $15 \mathrm{~kW}, 10 \mathrm{~kW}$, and $5 \mathrm{~kW}$ motor, respectively.

The regenerative torque acting on the vehicle's wheel is given by

$$
T_{\text {reg,wheel }}=T_{\text {reg }} \cdot \eta_{\text {trans }} \cdot r
$$

where the transmission ratio, $r$, is given by $r=$ motor speed/ wheel speed.

The motor speed can be calculated from the vehicle speed using

$$
N_{\text {motor }}(t)=V(t) \cdot \frac{1 \mathrm{rev}}{2 \pi R_{\text {tyre }}} \cdot 60 \cdot r .
$$

The braking force due to the regenerative torque can then be calculated from

$$
F_{\text {reg }}(t)=\frac{T_{\text {reg,wheel }}(t)}{R_{\text {tyre }}}
$$

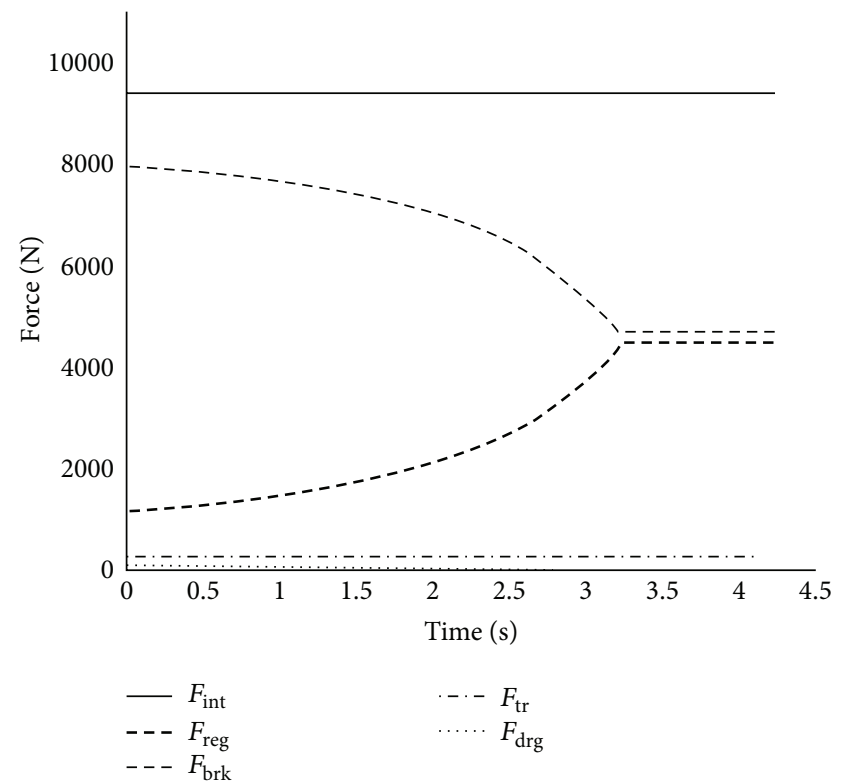

FIGURE 7: Variation of inertial and regenerative braking, braking, and tractive and drag forces as a function of time.

The braking force is simply the difference between the forward inertial force and the other retarding forces:

$$
F_{\text {brk }}(t)=F_{\text {int }}-F_{\text {reg }}(t)-F_{\text {dg }}(t)-F_{\text {tr }}
$$

The energy captured by the recuperation mechanism and that dissipated in the brakes are given by

$$
\begin{aligned}
& E_{\mathrm{reg}}=\int_{0}^{t} F_{\mathrm{reg}}(t) \cdot V(t) d t, \\
& E_{\mathrm{brk}}=\int_{0}^{t} F_{\mathrm{brk}}(t) \cdot V(t) d t .
\end{aligned}
$$

Legislation requirements specify that vehicles from M1 (M1 category belongs to passenger cars that do not exceed eight seats including the driver's seat.) category should be designed to decelerate to a complete stop at a minimum of $6.43 \mathrm{~m} / \mathrm{s}^{2}$ or $0.66 \mathrm{~g}$ from speeds up to $100 \mathrm{~km} / \mathrm{h}$. Thus, substituting an initial velocity of $100 \mathrm{~km} / \mathrm{h}$ into (1) and an acceleration value of $-0.66 \mathrm{~g}$ into (2), solving (3), (4), (8), and (9) yields the quantitative value of forces that act on the simulated vehicle during recuperation mode. The variation in braking forces, the traction, and the aerodynamic drag forces during the simulating braking event is shown in Figure 7. 


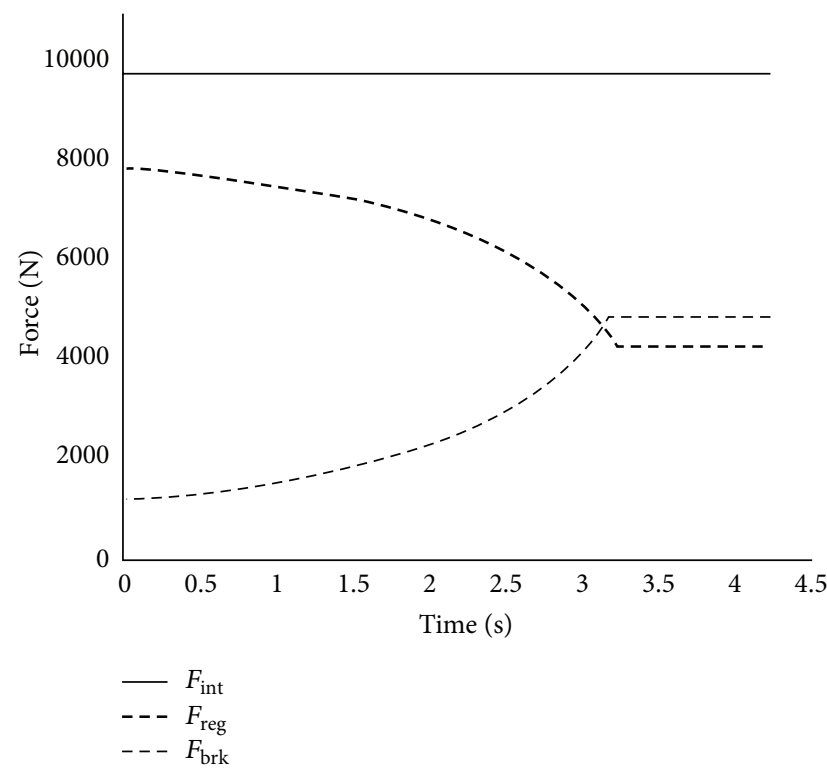

(a)

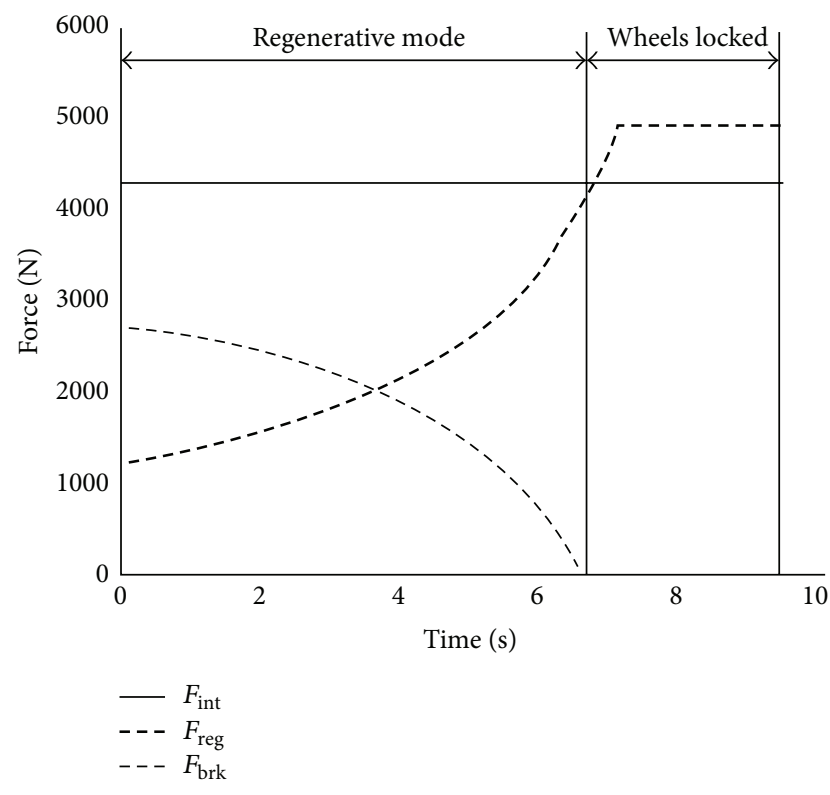

(b)

FIGURE 8: Variation in the braking forces $\left(F_{\text {reg }}\right.$ and $\left.F_{\text {brk }}\right)$ with respect to time in comparison to the forward inertial force: (a) with a deceleration rate of $0.66 \mathrm{~g}$ and $(\mathrm{b})$ with a deceleration rate of $0.30 \mathrm{~g}$.

Analysis of Figure 7 reveals that the magnitude of the traction and aerodynamic drag forces are small in comparison to the regenerative and frictional braking forces and thus can be ignored in subsequent calculations. The plot also reveals that the traction motor of simulated vehicle was not powerful enough to produce the regenerative braking force demanded by the situation. To compensate, the brakes have been applied to effectively counter the forward inertial force. The application of the brakes results in recoverable energy to be wasted. A higher power motor could be used to suppress this wastage. However, as identified in Figure 6, the usage of high power motor will result in an increased weight penalty as $m_{1}>m_{2}>m_{3}$. In addition, the battery may not have the capability to absorb the large surge in regenerated power produced by a high-powered motor.

An alternative method to increase the absorption of the recuperated energy while using a less power motor is addition of an auxiliary (AUX) regenerative load. The auxiliary unit can be clutched with the traction motor during braking events to increase the regenerative load. Literature review uncovered that the $\mathrm{A} / \mathrm{C}$ unit requires substantial amount power (about $2-3 \mathrm{~kW}$ ) and operates nearly $50 \%$ of vehicle utilisation time [3]. Furthermore, EVs typically employ a dedicated motor to operate the compressor at its desired speed. By integrating the $\mathrm{A} / \mathrm{C}$ compressor with the traction motor, the added regenerative load will improve the power absorbing capacity of the recuperation mechanism without the requirement to upgrade the traction motor's power rating.

Two independent simulations were performed to study the implications of adding an auxiliary regenerative load during a braking event. Figures 8(a) and 8(b) show the variation in braking forces for these two simulations. For both simulations, the total regenerative load was set at
TABLE 2: Comparison of regenerative braking with and without the AUX load of $3 \mathrm{~kW}$.

\begin{tabular}{lccccc}
\hline & $a$ & $\begin{array}{c}\text { Regenerative } \\
\text { load }\end{array}$ & $E_{\text {reg }}$ & $E_{\text {brk }}$ & $E_{\text {reg }} / E_{\text {brk }}$ \\
\hline Without & $-0.66 \mathrm{~g}$ & $35 \mathrm{~kW}$ & $118 \mathrm{~kJ}$ & $425 \mathrm{~kJ}$ & 0.278 \\
AUX & & & $128 \mathrm{~kJ}$ & $415 \mathrm{~kJ}$ & 0.308 \\
With AUX & $-0.66 \mathrm{~g}$ & $38 \mathrm{~kW}$ & 1278 \\
\hline
\end{tabular}

$38 \mathrm{~kW}$, a $3 \mathrm{~kW}$ increase compared to the previous simulation $(35 \mathrm{~kW})$. The additional $3 \mathrm{~kW}$ load models the coupling of $\mathrm{A} / \mathrm{C}$ compressor with the traction motor in a braking event to produce a step increase in the total regenerative load. The first simulation was conducted with a deceleration rate of $0.66 \mathrm{~g}$ while the second was performed at $0.30 \mathrm{~g}$. Comparing Figure 8(a) with Figure 7, the addition of $3 \mathrm{~kW}$ auxiliary load has increased the regenerative braking force thereby minimising the energy wasted in brake pads. Table 2 provides a quantitative comparison in the energy recoverability for the cases with and without $3 \mathrm{~kW}$ auxiliary load. It can observed that an $8 \%$ increase in the regenerative load $(3 \mathrm{~kW})$ improves $E_{\text {reg }} / E_{\text {brk }}$ ratio by $10 \%$. The key benefit of clutching the auxiliary load is that it permits the usage of $35 \mathrm{~kW}$ motor while increasing the recovered energy. There will be no change in the vehicle's weight as the proposed technique simply shifts the location of the existing A/C compressor to permit the mechanical clutching of $\mathrm{A} / \mathrm{C}$ compressor with the traction shaft.

Figure $8(\mathrm{~b})$ depicts the simulation results when the vehicle decelerates at a rate of $0.30 \mathrm{~g}$. Based on the plot, it can be observed that a combination of lower deceleration rate and added regenerative load causes the wheels to lock after six seconds as the regenerative braking force exceeds the forward 


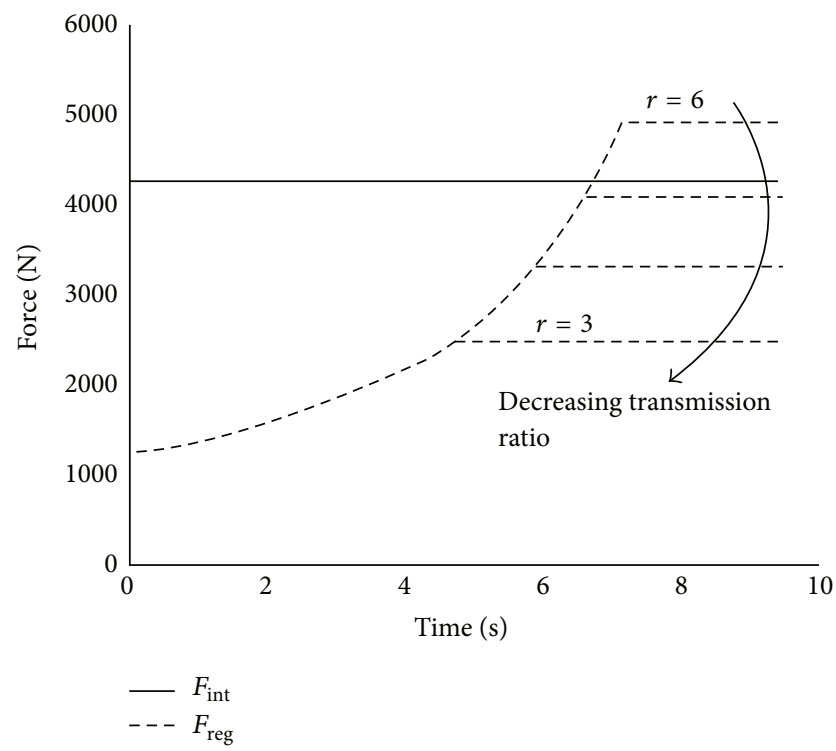

FIGURE 9: Decreasing the regenerative braking force by varying the transmission ratio.

inertial force. Though this situation is dangerous, it can be easily avoided by reducing the regenerative braking torque either by decreasing the transmission ratio (Figure 9) or by limiting the current generated by the traction motor.

\subsection{Battery Energy Saving Simulation}

3.3.1. Simulation Setup. Simulink has been used to study the reduction in battery energy consumption achieved by integrating the $\mathrm{A} / \mathrm{C}$ compressor (or any auxiliary unit) with the traction drive. For the study, a MATLAB ${ }^{\circledR}$ based computer program, Advanced Vehicle Simulator (ADVISOR) [8], which specialises in vehicle modelling, has been extensively modified to facilitate the simulation studies. An overview of the graphical setup in Simulink is shown in Figure 10. For the analysis, the standard EV block diagram was modified such that all electrical accessories/loads other than the A/C unit remain disabled. In addition, it is assumed that the components such as the wheels, final drive, gearbox, battery, and clutch operate without any inefficiencies. To simplify the modelling process, the $\mathrm{A} / \mathrm{C}$ compressor is assumed to operate at its peak power $(3 \mathrm{~kW})$ throughout the analysis. The principal rationale for these assumptions is to isolate the $\mathrm{A} / \mathrm{C}$ compressor load and to discover the improvements in efficiency gains attained by minimising the energy transformations from one domain to another (e.g., mechanical to electrical). An energy meter block was used to record the total energy discharged from the battery for a given simulation.

With reference to Figure 10, notice that the A/C compressor with a power load of $3 \mathrm{~kW}$ obtains its operating power via two distinct sources: (1) compressor motor and (2) recuperated mechanical energy. When the vehicle recuperates, the recuperation power isolator analyses the quantity of recuperated power and activates the clutch mechanism only if the regenerated power exceeds the A/C compressor load (power flow path 1). The clutch physically connects the $\mathrm{A} / \mathrm{C}$ compressor with the traction motor and permits immediate utilization of the recuperated mechanical energy thereby eliminating energy losses due to energy conversion. The engagement of the clutch disconnects the compressor motor from the battery, thereby conserving stored energy, whereas, when the vehicle is not operating in regenerative mode, a dedicated motor obtains the power from the battery and drives the $\mathrm{A} / \mathrm{C}$ compressor (power flow path 3 ).

When the energy flows through path 2 (regenerative braking), it does not undergo any form of transformation as the mechanical energy arriving at the motor shaft can be channelled directly to drive the A/C compressor. Therefore, this energy flow path is assumed to be free from any losses. Any excess power generated during the regenerative braking will be delivered to battery through energy flow path 2 for later utilization. However, in this case, the mechanical energy arriving at the motor shaft has to be first converted to electrical energy by the motor and subsequently to electrochemical energy to be stored in the battery. These energy transformations will incur losses, which has been accounted for by the introduction of $\eta_{1}$. When the vehicle operates in drive mode, the A/C compressor motor obtains its energy from the battery. Then again, the electrochemical energy contained in the battery has to be transformed and conditioned using a DC-to-DC converter to a form suitable to be used by the compressor motor. The inefficiency associated with this power flow path has been accounted for by introducing $\eta_{2}$.

An electric generator converts the mechanical energy to electrical energy with a typical value of 95.0\% [9]. Likewise, the efficiency of energy conversion in a battery from chemical to electrical (and vice versa) occurs with an efficiency of $90.0 \%$ [9]. Since the energy flow through path 1 undergoes two energy transformations (mechanical $\rightarrow$ electrical $\rightarrow$ electrochemical), the net efficiency associated with path 1 can be assigned to be $\eta_{1}=85.5 \%$. Likewise, the energy flowing through path 3 undergoes a similar energy transformation that occurred in path 1 , but in reverse order. However, the conversion of energy from electrical to mechanical occurs at $65 \%$ for the case of small motors [9] (compressor motor). Therefore, the net efficiency of $\eta_{2}=61.8 \%$ can be assigned to path 3 . The striking outcome of this analysis is that the regenerative energy delivered at the $\mathrm{A} / \mathrm{C}$ compressor through paths 2 and 3 has net efficiency of $\eta_{1} \cdot \eta_{2}=52.8 \%$. This reveals that nearly half of the recuperated energy captured by the regenerative braking mechanism is lost before it arrives at the A/C compressor.

3.3.2. Drive Cycle and Regenerative Power. A drive cycle is a schedule that governs the vehicle's speed as a function of time, which is essentially a mathematical representation of a road. It is a key input for vehicle simulation as it facilitates producing a repeatable experiment for performance comparison. The paper simulated the test vehicle using five EU legislative cycles listed in Table 3 using ADVISOR [8]. During the investigation, the simulated vehicle was driven in the selected drive cycle and the total braking time for each cycle was recorded. Based on the results gathered from the study, it can be observed that the aggressive drive cycles such as ECE 15, ECE 15+EDUC, and NEDC have a substantial period 


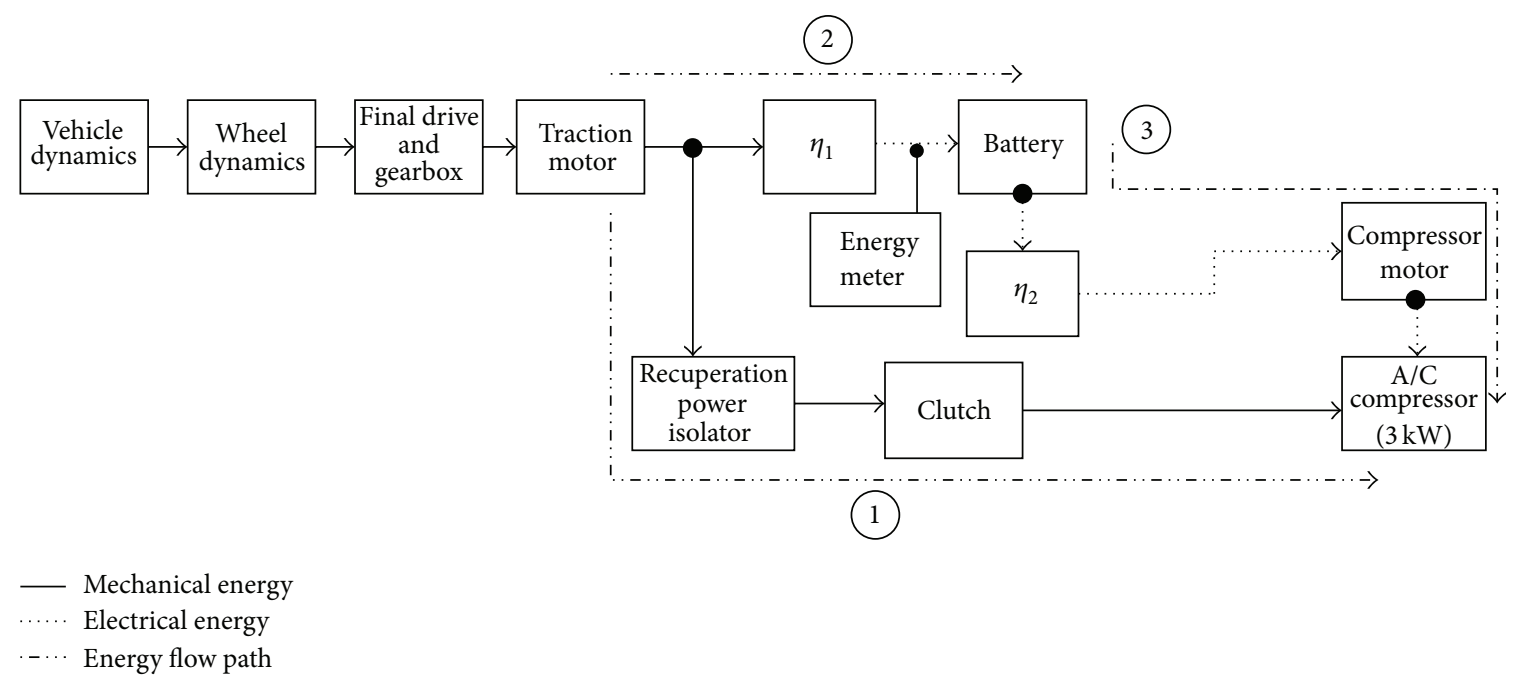

FIGURE 10: The graphical setup in Simulink for predicting the efficiency improvement.

TABLE 3: EU legislative cycle analysis.

\begin{tabular}{lcccc}
\hline Drive cycle & Distance & Total time & $\begin{array}{c}\text { Braking } \\
\text { time }\end{array}$ & $\begin{array}{c}\% \text { braking } \\
\text { time }\end{array}$ \\
\hline ECE 15 & $1.0 \mathrm{~km}$ & $195 \mathrm{~s}$ & $41.2 \mathrm{~s}$ & $21.1 \%$ \\
EUDC & $7.0 \mathrm{~km}$ & $400 \mathrm{~s}$ & $48.0 \mathrm{~s}$ & $12.0 \%$ \\
EUDC, low & $10.6 \mathrm{~km}$ & $1224 \mathrm{~s}$ & $103.0 \mathrm{~s}$ & $8.4 \%$ \\
ECE 15 + & $10.9 \mathrm{~km}$ & $1225 \mathrm{~s}$ & $201.8 \mathrm{~s}$ & $16.5 \%$ \\
EUDC & $10.9 \mathrm{~km}$ & $1184 \mathrm{~s}$ & $204.3 \mathrm{~s}$ & $17.3 \%$ \\
NEDC & & & &
\end{tabular}

of braking events. On average, a vehicle spends $15 \%$ of its total time in braking, signifying an immense potential in recoverable energy for all drive cycles.

For the purpose of discussion, consider the test vehicle to be operated under ECE $15+$ EUDC drive cycle. The scheduled velocity versus time for the stated drive cycle is shown in Figure 11(a), while Figure 11(b) shows the regenerative power produced by the simulated vehicle during recuperation events. It can be observed that the magnitude and the duration of regenerative power are proportional to the rate of change in vehicle's velocity (deceleration rate). Examining Figures $11(\mathrm{a})$ and $11(\mathrm{~b})$, it can be noted that abrupt velocity changes result in producing large magnitude of regenerative power, but these events are short-lived thereby confining the regenerative power to a brief period of time.

The A/C compressor load has been superimposed over Figure 11(b) to highlight that not all regeneration events are capable of providing the necessary power to the $\mathrm{A} / \mathrm{C}$ compressor. For example, the first regeneration power peaks at about $1000 \mathrm{~W}$, which is less than half of the power required to meet the $\mathrm{A} / \mathrm{C}$ compressor load. Therefore, a drive cycle can consist of large percentage of braking time, but if the changes in velocity were gradual, it might not produce the sufficient regenerative power to drive the $\mathrm{A} / \mathrm{C}$ compressor.

Figures 11(a) and 11(b) compare the regenerative power, the $\mathrm{A} / \mathrm{C}$ compressor load, and the excess power as a function of time. Excess power represents the regenerative power that is available for storage after the consumption by the $\mathrm{A} / \mathrm{C}$ compressor. The recuperation power isolator block has been configured such that the clutch mechanism is only activated when the regenerative power exceeds the $\mathrm{A} / \mathrm{C}$ compressor load. Accordingly, the compressor motor has been configured to cut off when power flows through energy flow path 1 . This ensures that energy flow path 1 is activated only when the regenerative power arriving at the motor shaft is capable of driving the $\mathrm{A} / \mathrm{C}$ compressor without the need to operate the compressor motor. This effect can be verified by studying the variation in excess power depicted in Figure 12. Notice that the excess is reduced by the magnitude of the $\mathrm{A} / \mathrm{C}$ compressor load only when the regenerative power exceeds the compressor load. As with the conventional regenerative mechanism, the excess power is channelled to the battery for subsequent usage.

3.3.3. Reduction in Battery Energy Consumption. The reduction in battery energy consumption attained by integrating the $\mathrm{A} / \mathrm{C}$ compressor with the traction motor was accessed by simulating the test vehicle in the EU legislative drive cycles. During the simulation, the vehicle dynamics block was driven by the selected drive cycle and the energy consumed from the battery was measured for the two distinct cases: (1) A/C compressor motor operated from the battery and (2) A/C compressor operated by a combination of compressor motor and clutch (regenerative power). The percentage reduction in the expenditure of battery energy was then computed for each drive cycle and the results have been summarised in Figure 13. The percentage braking time associated with each drive cycle has been superimposed over the results as it indicates the availability of regenerative power. Analysis of the plot reveals that the improvement in the battery energy saving is proportional to the percentage braking time associated with each drive cycle. This result is expected as higher number of braking events will provide higher opportunity 


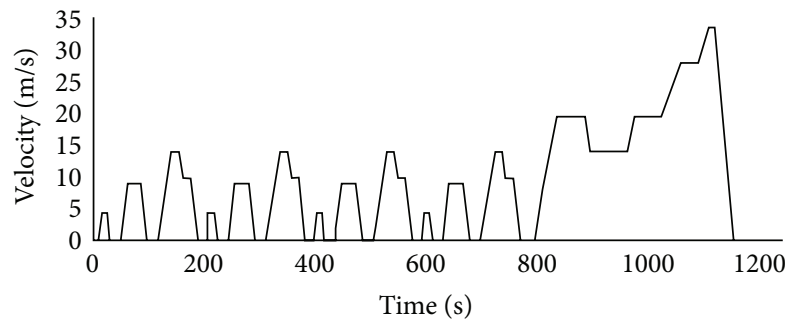

(a)

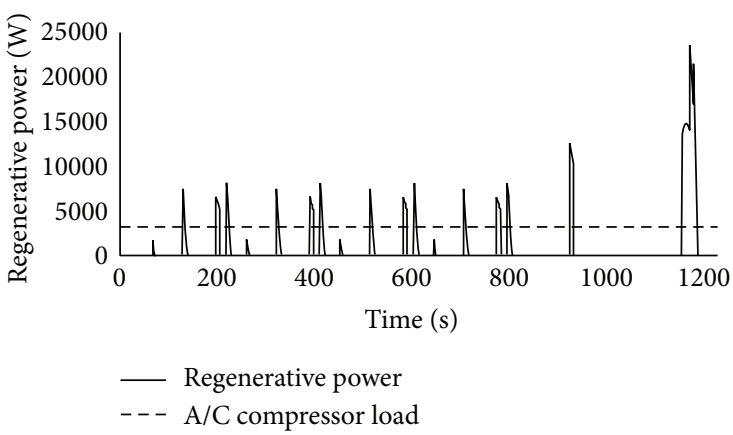

(b)

FIGURE 11: Simulated vehicle’s (a) velocity and (b) regenerative power on ECE 15 + EDUC drive cycle.

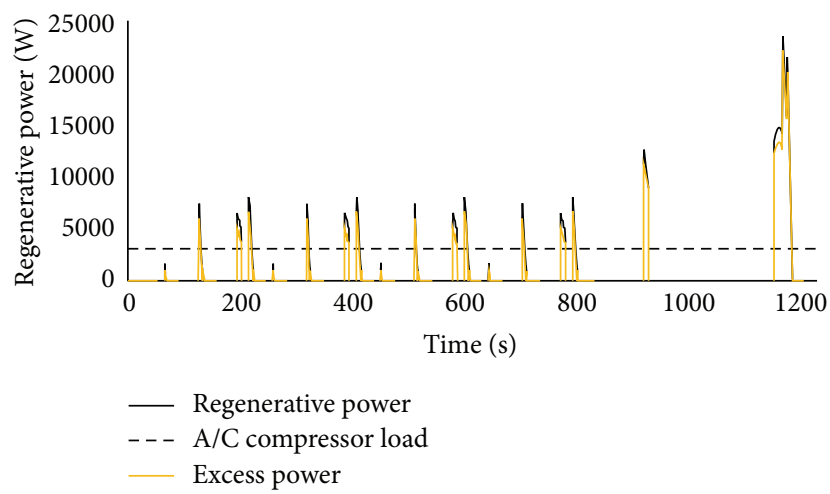

FIGURE 12: Excess regenerative power directed to the battery.

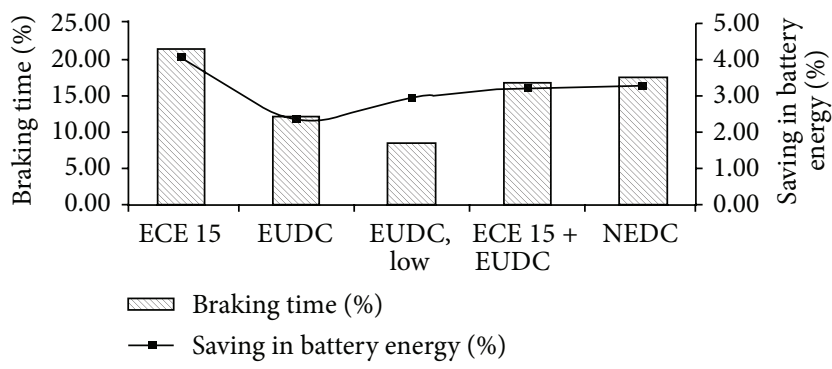

Figure 13: Percentage saving in battery energy for a test vehicle simulated in EU drive cycles with the $\mathrm{A} / \mathrm{C}$ compressor operated using a combination of compressor motor and clutch.

of the regenerative braking mechanism to operate the $\mathrm{A} / \mathrm{C}$ compressor through the clutch.

With reference to Figure 13, the integration of $\mathrm{A} / \mathrm{C}$ compressor with the traction drive reduces the battery consumption by an average of $3.2 \%$. This improvement in battery energy saving will directly translate into increasing the cruise range of the EV. Though this improvement appears to be marginal, it is expected that the percentage saving in battery energy will be higher in reality. This is because the simulation ignored a number of other losses associated with energy flow paths 2 and 3. For example, the energy losses along path 2 did not account for possible devices such as a DC-to-DC or an AC-to-DC converter and an electrical charger. Likewise, inverters that operate the $\mathrm{A} / \mathrm{C}$ compressor motor have been ignored along path 3 .

\section{Design}

4.1. Motor Design. Figure 14 illustrates the schematic diagram of a design that integrates the $\mathrm{A} / \mathrm{C}$ compressor with the traction drive. The design adopts a concentric shaft arrangement to achieve coaxial placement of the traction and the compressor drives. The concentric shafts provide the flexibility to independently control the torque and speed of the traction and compressor drives without any form of interaction between the drives. Hence, the $\mathrm{A} / \mathrm{C}$ compressor can be operated at its full capacity even when the vehicle is at a complete standstill. During normal driving mode, the torque generated in rotors one and two drives the $\mathrm{A} / \mathrm{C}$ compressor and the vehicle, respectively. During recuperation mode, the application of brakes activates the clutch, which physically connects the traction motor with the compressor drive. The clutch facilitates the transfer of energy arriving at the traction drive to the compressor and eliminates the need for energy conversion, thereby eliminating energy transformation losses. The engagement of the clutch disconnects the electrical power supply to rotor one to conserve the battery energy.

\section{Conclusion}

Cabin air conditioning and long cruise range are the key features required to increase the market penetration of EV. However, studies reveal that cabin air conditioning has an immense impact on the range performance of the EV. Adding battery capacity to compensate for the poor range performance is not a practical solution as it inadvertently increases both the structural weight and the capital cost of the $\mathrm{EV}$. Literature review identified that the cruise range of an EV can decrease by 22 to $48 \%$ depending on the $\mathrm{A} / \mathrm{C}$ usage. The review coveys the necessities to identify means to enhance the efficiency of $\mathrm{A} / \mathrm{C}$ to mitigate its impact on the cruise range of the EV. The review also identified that integrating the compressor and traction drive decreases component count and material cost and improves the reliability. 


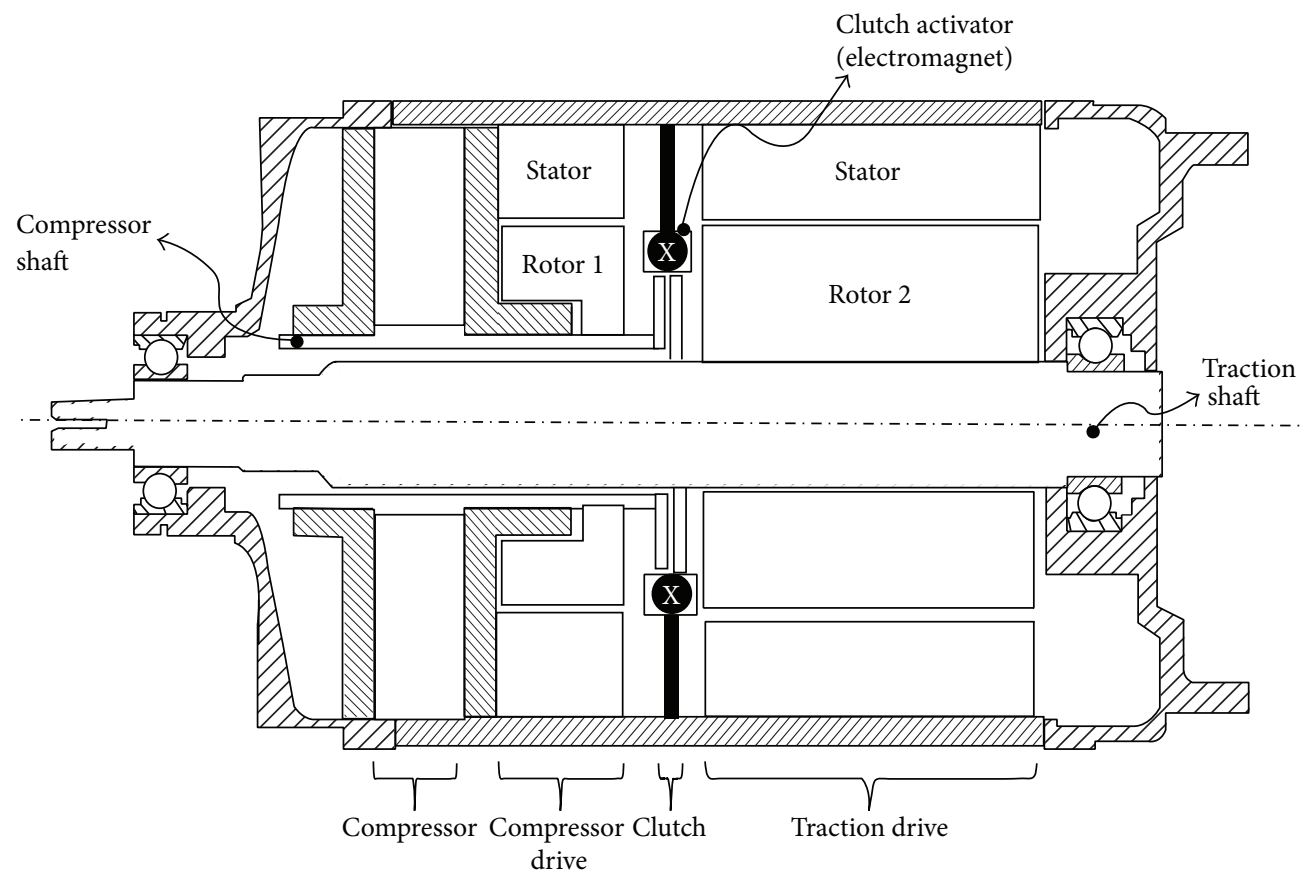

FIGURE 14: Concept of the integration of an air-conditioning compressor into the drive motor of an Electric Vehicle.

When a conventional car brakes, the forward momentum of the car is primarily dissipated as heat energy in the brake pads. Undoubtedly, this not only results in energy wastage, but also expedites the wear rate of the brake pads. To counter this, hybrid vehicles and EVs are fitted with regenerative braking mechanism. This paper set out to improve the regenerative braking mechanism by integrating an $\mathrm{A} / \mathrm{C}$ compressor with the traction drive. The objective of such an integration is to improve the energy recovering capacity of regenerative braking mechanism and reduce the energy consumed from the battery. Based on the analysis performed on a midsize EV, it was shown that the energy recovering capacity of the regenerative braking mechanism improves by $8 \%$ when a $3 \mathrm{~kW}$ A/C compressor acts in unison with a $35 \mathrm{~kW}$ traction motor during braking events. In addition, subsequent simulations showed that the power consumed from the battery reduces by an average of $3.2 \%$ due to the elimination of energy conversion losses.

A design solution fulfilling the requirements of the regenerative braking mechanism explored by the paper was discussed. The design integrates the $\mathrm{A} / \mathrm{C}$ compressor, the compressor drive motor, and the traction motor into single housing. This setup facilitates the traction motor to physical clutch with the A/C compressor during braking events and facilitates the immediate utilisation of the captured energy without the necessity for any energy conversion processes. Though the compressor and traction motors are contained in single housing, the interference between these motors is eliminated through the usage of coaxial shafts. This mechanical configuration permits independent speed control over the drives during normal operating modes of the vehicle. The paper also identified the rotary piston compressor as a viable choice for the proposed motor design.

\section{Nomenclature}

\section{Parameters}

a: Acceleration $\left(\mathrm{m} / \mathrm{s}^{2}\right)$

A: Frontal area $\left(\mathrm{m}^{2}\right)$

$C_{d}$ : Coefficient of drag

$E$ : Energy $(\mathrm{kJ})$

$F$ : Force $(\mathrm{N})$

g: Gravitational constant $\left(\mathrm{m} / \mathrm{s}^{2}\right)$

$m$ : Mass $(\mathrm{kg})$

$N$ : Revolutions per minute (RPM)

$P$ : Power $(\mathrm{kW})$

$r$ : Transmission ratio

$R:$ Radius (m)

$t$ : Time (s)

$T:$ Torque $(\mathrm{Nm})$

$V: \operatorname{Velocity}(\mathrm{m} / \mathrm{s})$.

\section{Greek Letters}

$\eta$ : Efficiency

$\mu$ : Coefficient of friction

$\rho$ : Air density $\left(\mathrm{kg} / \mathrm{m}^{3}\right)$.

\section{Subscripts}

$b$ : $\quad$ Base speed

gen: Generation

max: Max

$0: \quad$ Initial

int: Inertial force

dg: Drag force

tr: Tractive force

$w$ : Weight 
reg: Regenerative braking force

trans: Transmission

brk: Brake force.

\section{Conflict of Interests}

The author declares that there is no conflict of interests regarding the publication of this paper.

\section{References}

[1] B. B. Owens, F. R. Kalhammer, A. Kozawa, and C. B. Moyer, Performance and Availability of Batteries for Electric Vehicles: Report of the Battery Technology Advisory Panel, California Air Resources Board, El Monte, Calif, USA, 1995.

[2] S. Fischer and J. Sand, "Total environmental warming impact (TEWI) calculations for alternative automotive airconditioning systems," in Proceedings of the SAE International Congress and Exposition, Detroit, Mich, USA, February 1997.

[3] S. K. Fischer, "Comparison of global warming impacts of automobile air-conditioning concepts," in Proceedings of the International CFC and Halons Alternative Conference, Washington, DC, USA, October 1995.

[4] J. T. Lee, S. Kwon, Y. Lim, M. S. Chon, and D. Kim, "Effect of air-conditioning on driving range of electric vehicle for various driving modes," SAE Technical Paper 2013-01-0040, 2013.

[5] R. Farrington and J. Rugh, "Impact of vehicle air-conditioning on fuel economy, tailpipe emissions, and electric vehicle range," Tech. Rep. NREL/CP-540-28960, National Renewable Energy Laboratory, Golden, Colo, USA, 2000.

[6] K. Umezu, "Air conditioning system for electric vehicle (iMiEV)," in Proceedings of the SAE Automotive Refrigerant \& System Efficiency Symposium, JSAE Review, Scottsdale, Ariz, USA, July 2010.

[7] G.-J. Su and J. S. Hsu, "An integrated traction and compressor drive system for EV/HEV applications," in Proceedings of the 20th Annual IEEE Applied Power Electronics Conference and Exposition (APEC '05), vol. 2, pp. 719-725, IEEE, Austin, Tex, USA, March 2005.

[8] T. Markel, A. Brooker, T. Hendricks et al., "ADVISOR: a systems analysis tool for advanced vehicle modeling," Journal of Power Sources, vol. 110, no. 2, pp. 255-266, 2002.

[9] C. M. Summers, "The conversion of energy," Scientific American, vol. 225, no. 3, pp. 148-160, 1971. 


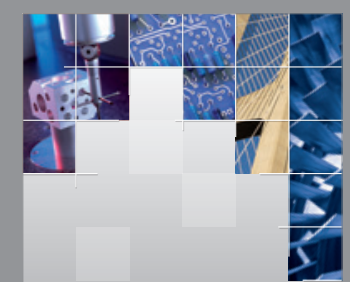

\section{Enfincering}
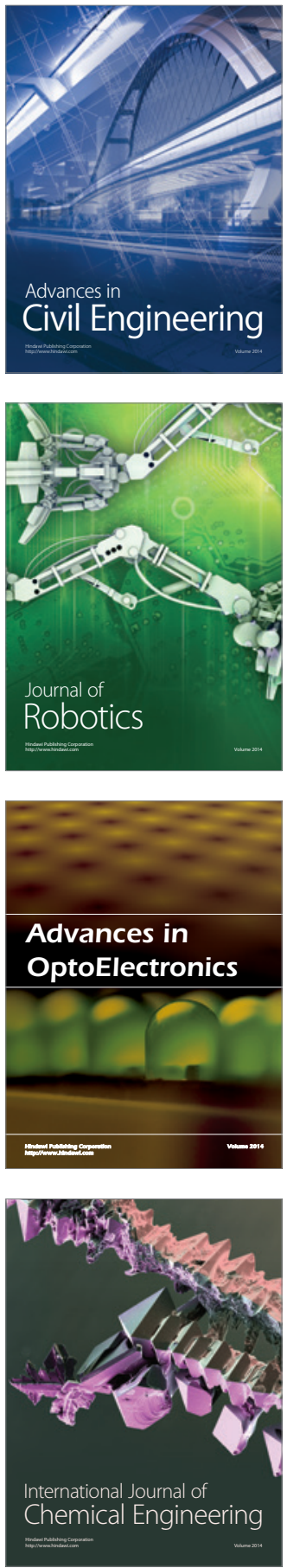

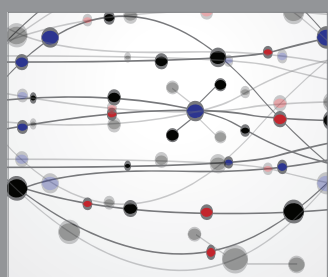

The Scientific World Journal

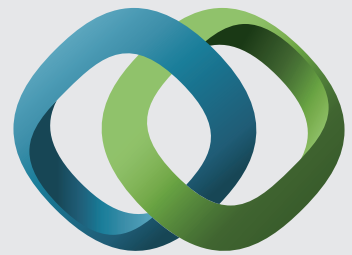

\section{Hindawi}

Submit your manuscripts at

http://www.hindawi.com
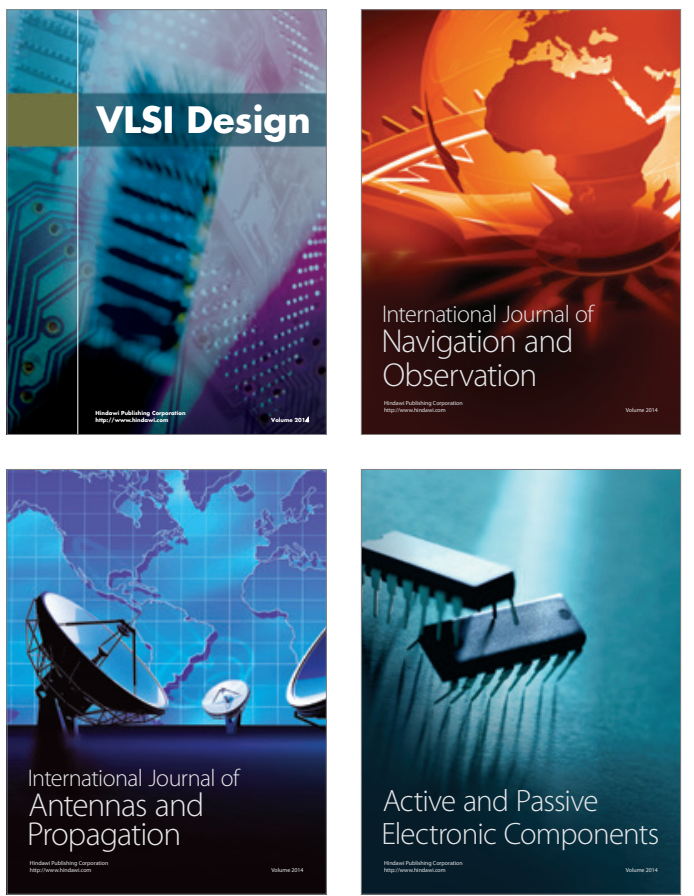
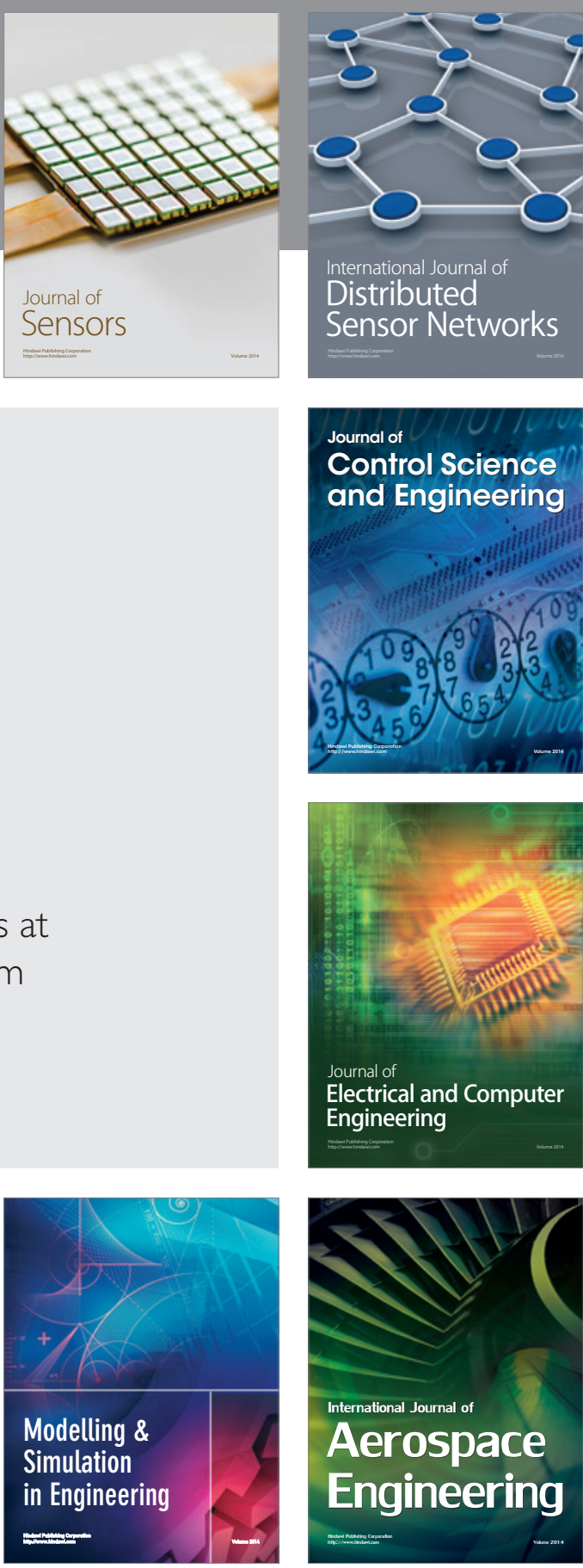

International Journal of

Distributed

Sensor Networks

Journal of

Control Science

and Engineering
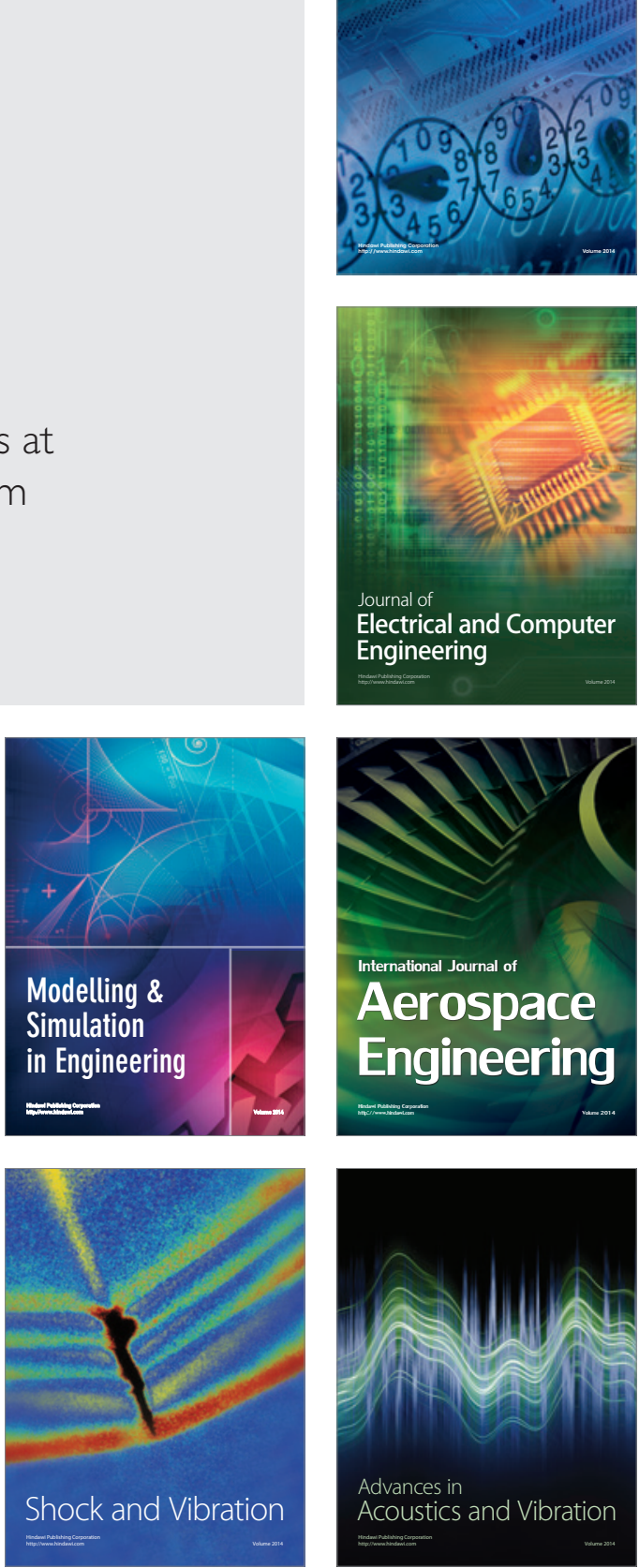